economic viability as a result of the differences in sites and practices. They estimated that carbon prices of less than AUD\$18 per ton of carbon dioxide equivalent are sufficient to make carbon offset investments in low-productivity land viable. Economic viability is generally largest for farm forestry plantings in areas of high rainfall, whereas plantings in areas of low rainfall are less profitable.

Compared with existing agricultural enterprises, such as sheep or cattle grazing, employment from carbon offsets in marginal lands is small, but the jobs generated would be additional to current on-farm employment.

ADAPTATION

\section{Flexible water investments} Climatic Change http://doi.org/h2w (2012)

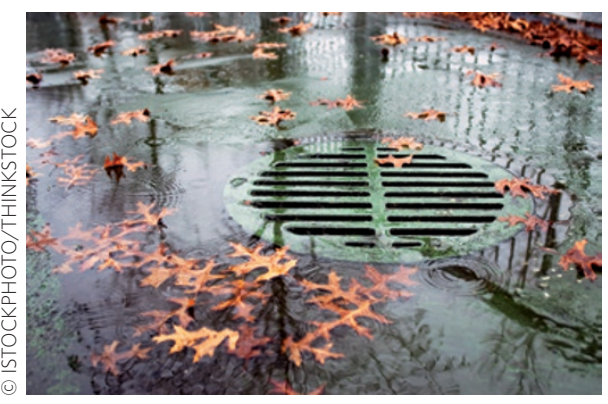

Investments in urban drainage and flood protection are based on impact assessments under a specified climate change scenario to identify a singular optimal adaptive strategy. However, such an approach is risky under a rapidly changing climate.

Berry Gersonius, of the UNESCOIHE Institute for Water Education, The Netherlands, and colleagues advocate for a managed/adaptive strategy that allows investors to adjust to future uncertainties as they unfold, and propose 'real in options' (RIO) analysis as an appropriate method. $\mathrm{RIO}$ analysis is based on a multiple-step optimization model that includes setting scenarios for an uncertain process, identifying investment options under the different scenarios and optimizing them in terms of key objectives and constraints. They test the method in the case of an existing urban drainage system in West Garforth, England. They identify an optimal set of adaptive strategies with an expected net present cost of $£ 1.70$ million. The standard strategy of adapting to a single scenario would deliver, for the worst climate change path, a net present cost of $£ 2.13$ million.
CARBON STORAGE

\section{Permafrost ponds}

Glob. Biogeochem. Cycles http://doi.org/ $\mathrm{h} \times 4$ (2012)

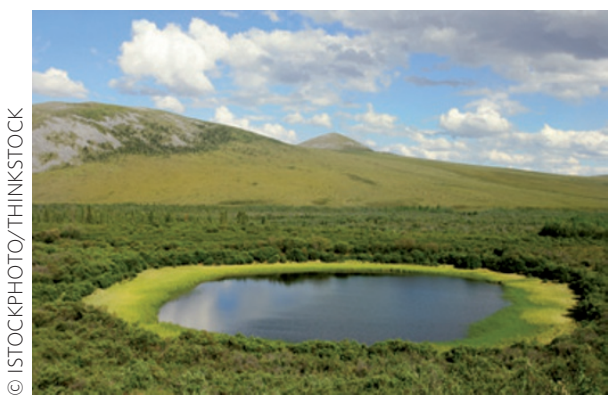

Permafrost holds a large reserve of organic carbon - estimated to be $\sim 50 \%$ of the global belowground stock. Melting permafrost may result in a large release of this carbon as carbon dioxide or methane, which would be a positive climate change feedback. Substantial carbon emissions have been observed from lakes in permafrost areas, but the emissions from small ponds are not taken into global emission estimates as they are invisible to most satellites.

Anna Abnizova, of the Alfred Wegener Institute, Potsdam, Germany, and colleagues, studied water bodies on Samoylov Island, northeastern Siberia - a continuous permafrost zone. They quantified the carbon flows and carbon dioxide emissions from lakes, ponds and outlets.

Carbon dioxide emissions from lakes and ponds, which cover 25 per cent of the island, accounted for 74-81per cent of net emissions - 28-43 per cent of the total was from ponds and 27-46 per cent from lakes. Excluding ponds from total summer carbon dioxide emissions results in an underestimation of 35-62 per cent. Ponds in permafrost regions are too small to be represented in current model simulations, but the authors conclude that they should be included in future estimates. $B W$

\section{CLIMATE MODELLING}

\section{Asian aerosol influence \\ Geophys. Res. Lett. 39, L11703 (2012)}

Black-carbon aerosols in the atmosphere can absorb sunlight and cause local surface dimming. Asian carbon aerosol emissions may continue to grow in the coming years, and have been shown to have an impact not only on a regional scale but also on global circulation and climate.

Haiyan Teng and co-workers, from the National Center for Atmospheric Research, USA, used a fully coupled global climate model to investigate the effect of increases in Asian carbon aerosol emissions on US temperatures, over the period 2005-2024. They simulate three scenarios with increases in Asian carbon aerosols of two, six and ten times the control.

The two higher scenarios produce an average warming of $\sim 0.4{ }^{\circ} \mathrm{C}$ for the US East Coast during winter, and over the entire United States in the summer. Such warming is caused by general circulation change, resulting from the increased Asian blackcarbon aerosols. This study reports warming in addition to that already expected from anthropogenic emissions.

\section{URBAN CLIMATE}

\section{Defining local zones}

Bull. Am. Meteorol. Soc. http://doi.org/ $\mathrm{h} \times 5$ (2012)

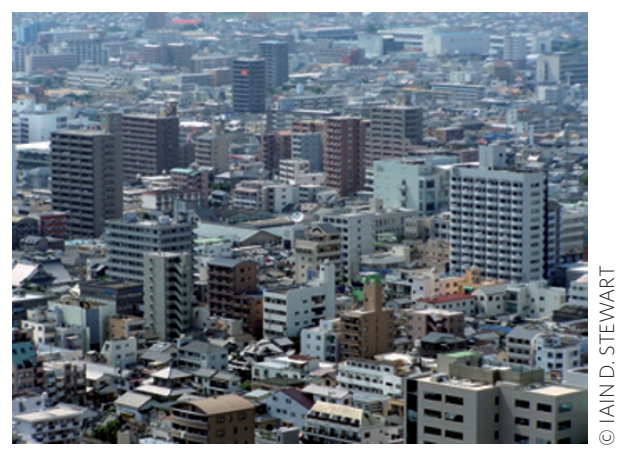

Urban development can lead to localized temperature increases, known as urban heat islands. They can occur in all urban areas, regardless of size or climate. This effect has been reported worldwide and can have implications for climate records. The differential between urban and rural temperature needs to be better defined, to ensure climate records are not compromised by this effect.

Iain Stewart and Tim Oke, of the University of British Columbia, Canada, have developed a classification system of 'local climate zones'. This system defines 17 zone types at the local scale $\left(10^{2}-10^{4}\right.$ metres $)$. Each zone is unique in its surface structure, land cover and human activity.

The system provides a climate-based classification of urban and rural areas for temperature studies. It has implications for urban-heat-island research, and will improve consistency and accuracy in urban climate reporting. Outcomes from the classification system will be helpful tools for planning authorities and climate change researchers. $B W$

Written by Alastair Brown, Monica Contestabile and Bronwyn Wake.

Corrected online: 6 July 2012 


\section{Correction}

The reference for the Research Highlight 'Flexible water investments' (Nature Clim. Change 2, 487; 2012) was incorrect; it should have read: Climatic Change http://doi.org/h2w (2012). Corrected in the HTML and PDF versions after print 6 July 2012 . 